\title{
The clival canal
}

\section{O canal clival}

In a skull of an approximately 35-year-old belonging to the didactical collection of the University of Santa Cruz do Sul, Brazil, it was noted the clival canal of the occipital portion of the clivus (Figure). According to recent descriptions ${ }^{1}$, a clival canal was identified in $1.6 \%$ of skulls and there is limited information on bony canals in the occipital part of the clivus. Moreover, the presence of clival canal hasn't been reported in classic anatomical textbooks.

The finding of a clival canal might interfere with neurosurgical operations in the clival region and possibly provoke symptoms of the basilar artery, as well as of the basilar plexus ${ }^{2}$. In addition, clinicians and radiologists should take into account this variability when managing cerebral venous disorders or interpreting imaging studies of the skull base ${ }^{3}$.

To our knowledge, there is no evidence in the current literature on the incidence of this variation in the population of our country. Thus, this report will be useful to increase the knowledge about this region that has considerable clinical interest ${ }^{2,4}$ (clival tumours had very high mortality and morbidity rates $)^{5}$, and finally to help promoting future studies in this area.

Deivis de Campos ${ }^{1,2}$, Geraldo Pereira Jotz ${ }^{3}$, Guilherme Reghelin Goulart ${ }^{2}$, Tais Malysz ${ }^{3,4}$

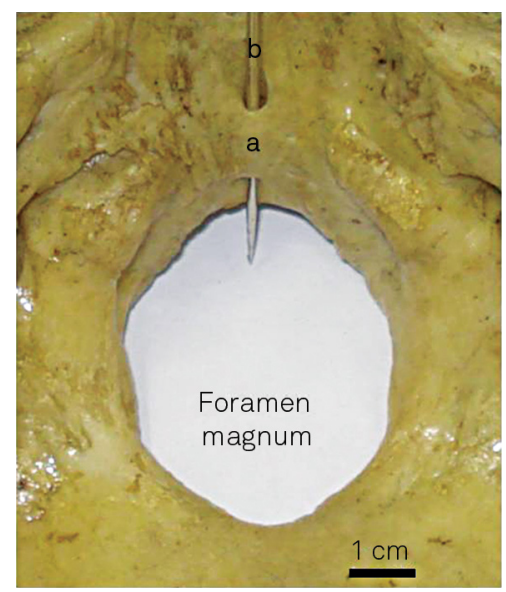

Figure. Internal view of the skull base with the presence of clival canal (a) being crossed by a histological needle (b). The shape is like a channel $9.1 \mathrm{~mm}$ in length and $1.9 \mathrm{~mm}$ in diameter. The canal was situated $3.5 \mathrm{~mm}$ in front the anterior border of the foramen magnum. In our observations we didn't find any indication of associated pathology this anatomical variation.

\section{References}

1. Paraskevas GK, Tsitsopoulos PP, Ioannidis OM. Incidence and purpose of the clival canal, a "neglected" skull base canal. Acta Neurochir (Wien). 2013;155(1):139-40. doi:10.1007/s00701-012-1570-3

2. Jalsovec $D$, Vinter I. Clinical significance of a bony canal of the clivus. Eur Arch Otorhinolaryngol. 1999;256(3):160-1. doi:10.1007/s004050050132

3. Tubbs RS, Hansasuta A, Loukas M, Louis RG Jr, Shoja MM, Salter EG et al. The basilar venous plexus. Clin Anat. 2007;20(7):755-9. doi:10.1002/ca.20494
4. Tubbs RS, Griessenauer CJ, Loukas M, Zurada A, Shoja MM, Cohen-Gadol AA. The enigmatic clival canal: anatomy and clinical significance. Childs Nerv Syst. 2010;26(9):1207-10. doi:10.1007/s00381-010-1100-7

5. Aktas U, Yilmazlar S, Ugras N. Anatomical restrictions in the transsphenoidal, transclival approach to the upper clival region: a cadaveric, anatomic study. J Craniomaxillofac Surg. 2013;41(6):457-67. doi:10.1016/j.jcms.2012.11.011

\footnotetext{
1 Universidade Federal de Ciências da Saúde de Porto Alegre, Departamento de Ciências Básicas da Saúde, Porto Alegre RS, Brazil; Universidade de Santa Cruz do Sul, Departamento de Biologia e Farmácia, Santa Cruz do Sul RS, Brazil;

${ }^{3}$ Universidade Federal do Rio Grande do Sul, Instituto de Ciências Básicas da Saúde, Departamento de Ciências Morfológicas, Porto Alegre RS, Brazil; «Universidade Federal de Goiás, Laboratório de Anatomia Humana e Comparada, Jataí Go, Brazil.

Correspondence: Deivis de Campos; Departamento de Ciências Básicas da Saúde, Laboratório de Anatomia Humana - UFCSPA; Avenida Sarmento Leite, 245; 90050-170 Porto Alegre RS, Brasil; E-mail: dcampos@ufcspa.edu.br

Conflict of interest: There is no conflict of interest to declare.

Received 19 April 2015; Received in final form 04 July 2015; Accepted 24 July 2015.
} 